\title{
Interactions between the ERK1/2 signaling pathway and PCAF play a key role in PE-induced cardiomyocyte hypertrophy
}

\author{
QIAN MAO ${ }^{1}$, SHUQI WU ${ }^{1}$, CHANG PENG $^{1}$, BOHUI PENG $^{1}$, \\ XIAOMEI LUO ${ }^{2}$, LIXIN HUANG ${ }^{1}$ and HUANTING ZHANG ${ }^{1}$ \\ ${ }^{1}$ Department of Pediatrics, Affiliated Hospital of Zunyi Medical University; ${ }^{2}$ Department of Physiology, \\ School of Basic Medical Sciences, Zunyi Medical University, Zunyi, Guizhou 563000, P.R. China
}

Received November 25, 2020; Accepted June 23, 2021

DOI: $10.3892 / \mathrm{mmr} .2021 .12275$

\begin{abstract}
Cardiomyocyte hypertrophy is a compensatory phase of chronic heart failure that is induced by the activation of multiple signaling pathways. The extracellular signal-regulated protein kinase (ERK) signaling pathway is an important regulator of cardiomyocyte hypertrophy. In our previous study, it was demonstrated that phenylephrine (PE)-induced cardiomyocyte hypertrophy involves the hyperacetylation of histone H3K9ac by P300/CBP-associated factor (PCAF). However, the upstream signaling pathway has yet to be fully identified. In the present study, the role of the extracellular signal-regulated protein kinase (ERK)1/2 signaling pathway in PE-induced cardiomyocyte hypertrophy was investigated. The mice cardiomyocyte hypertrophy model was successfully established by treating cells with $\mathrm{PE}$ in vitro. The results showed that phospho-(p-)ERK1/2 interacted with PCAF and modified the pattern of histone H3K9ac acetylation. An ERK inhibitor (U0126) and/or a histone acetylase inhibitor (anacardic acid; AA) attenuated the overexpression of phospho-ERK1/2 and H3K9ac hyperacetylation by inhibiting the expression of PCAF in PE-induced cardiomyocyte hypertrophy. Moreover, U0126 and/or AA could attenuate the overexpression of several biomarker genes related to cardiac hypertrophy (myocyte enhancer factor $2 \mathrm{C}$, atrial natriuretic
\end{abstract}

Correspondence to: Dr Chang Peng, Department of Pediatrics, Affiliated Hospital of Zunyi Medical University, 149 Dalian Street, Zunyi, Guizhou 563000, P.R. China

E-mail: pengchang_2006@126.com

Abbreviations: AA, anacardic acid; ANP, atrial natriuretic peptide; $\mathrm{BNP}$, brain natriuretic peptide; $\beta$-MHC, $\beta$-myosin heavy chain; Co-IP, co-immunoprecipitation; ChIP, chromatin immunoprecipitation; ERK, extracellular signal-regulated protein kinase; HAT, histone acetylase; H3K9ac, histone 3 acetylation K9; JNK, c-Jun N-terminal kinase; MEF2C, myocyte enhancer factor 2C; MAPK, mitogen-activated protein kinases; PE, phenylephrine; PCAF, P300/CBP-associated factor.

Key words: cardiomyocyte hypertrophy, ERK-signaling pathway, histone acetylation, anacardic acid peptide, brain natriuretic peptide and $\beta$-myosin heavy chain) and prevented cardiomyocyte hypertrophy. These results revealed a novel mechanism in that AA protects against PE-induced cardiomyocyte hypertrophy in mice via the ERK1/2 signaling pathway, and by modifying the acetylation of H3K9ac. These findings may assist in the development of novel methods for preventing and treating hypertrophic cardiomyopathy.

\section{Introduction}

Evidence is mounting to indicate that chronic heart failure (CHF) has become one of the primary causes of morbidity and mortality in modern society $(1,2)$. Unfortunately, the specific mechanisms underlying $\mathrm{CHF}$ remain unknown and the currently available treatments may only delay the progression of disease. Cardiac hypertrophy is a critical compensated stage that involves pathological remodeling of the myocardium, ultimately resulting in CHF (3). Therefore, it is vital to be able to prevent and treat cardiac hypertrophy to prevent the progression of cardiac remodeling into $\mathrm{CHF}$. In our previous study, it was shown that the imbalance in the modification of histone $\mathrm{H} 3 \mathrm{~K} 9 \mathrm{ac}$, a process mediated by histone acetylases (HATs), is involved in phenylephrine (PE)-induced cardiomyocyte hypertrophy (4). Several studies have shown that cardiac hypertrophy can be induced by the activation of multiple signaling pathways (5-8). The extracellular signal-regulated protein kinase (ERK) signaling pathway is considered to play a particularly important role in regulating pathological cardiac hypertrophy (9-11). Our previous study demonstrated that the HAT inhibitor, anacardic acid (AA), could attenuate PE-induced cardiac hypertrophy by regulating the modification of histone H3K9ac acetylation (4); however, the upstream signaling pathways were not determined.

To construct an animal model of myocardial hypertrophy, three commonly accepted methods are partial ligation of the thoracic aorta, arteriovenous fistula and subcutaneous injection of PE (12-15). In the present study, PE was used to induce cardiomyocyte hypertrophy in neonatal mice. Multiple studies have confirmed that PE can activate ERK1/2 pathway (16-18). Thus, the aim of the present study was to determine whether the interactions between the ERK1/2 signaling pathway and P300/CBP-associated factor (PCAF) served a key role in 
mediating H3K9ac acetylation in PE-induced cardiomyocyte hypertrophy.

\section{Materials and methods}

Experimental mice. All experimental animals were provided by the Experimental Animal Center of Chongqing Medical University. Clean and healthy neonatal Kunming male and female mice were used (1-3 days-of-age, weighing 2.3-2.7 g). All animal experiments were approved by the Animal Protection and Use Committee of Zunyi Medical University (Zunyi, China), and complied with Directive 2010/63/EU of the European Parliament (19).

Cell culture and treatment. Under aseptic conditions, Kunming mice (1-3 days-of-age) were sacrificed by decapitation. The ventricular tissue was immediately removed using ophthalmic scissors and cut into $1-2 \mathrm{~mm}^{3}$ pieces. The tissue was then ground in $1 \mathrm{ml} 0.05 \%$ collagenase type II (Worthington Biochemical Corporation) for $5 \mathrm{~min}$ at room temperature (repeated 8-10 times). Next, the supernatant was centrifuged at $1,500 \mathrm{x} \mathrm{g}$ for $10 \mathrm{~min}$ at room temperature, the supernatant was discarded and the cells resuspended in DMEM/F12 supplemented with 20\% FBS (HyClone; Cytiva). After $1.5 \mathrm{~h}$ of culture in an incubator at $37^{\circ} \mathrm{C}$ with $5 \% \mathrm{CO}_{2}$, the adherent fibroblasts were discarded and the cell suspension was transferred to a new culture flask. 5-BrdU (Beijing Solarbio Science \& Technology Co., Ltd.) was added to a final concentration of $0.1 \mathrm{mmol} / \mathrm{l}$ to prevent the growth of fibroblasts, and the cells were further cultured in an incubator. According to previous studies (20-24), the cells were treated with $100 \mu \mathrm{mol} / \mathrm{l} \mathrm{PE}$ (MedChemExpress; cat. no. HY-B0769), $50 \mu \mathrm{mol} / 1$ AA (Sigma-Aldrich; Merck $\mathrm{KGaA}$; cat. no. 16611-84-0) or $10 \mu \mathrm{mol} / 1 \mathrm{U} 0126$ (Selleck Chemicals; cat. no. S1102). Cardiomyocytes were treated with the aforementioned drugs individually or in combination, dependent on the treatment groups.

Cell viability assay. Cardiomyocytes were plated in a 96-well plate at a density of $2 \times 10^{4}$ cells/well. Next, $10 \mu \mathrm{l}$ Cell Counting Kit-8 (CCK-8) solution (Beijing Solarbio Science \& Technology Co., Ltd.) was added and cells were cultured for $4 \mathrm{~h}$ at $37^{\circ} \mathrm{C}$ in the dark. Finally, the absorbance was measured at $450 \mathrm{~nm}$ using a Universal Microplate Spectrophotometer (Bio-Rad Laboratories, Inc.).

Western blotting. Cardiomyocytes were used in western blotting at a density of $3-4 \times 10^{6}$ cells/well. Nuclear protein was harvested from mouse cardiomyocytes using a nuclear protein extraction kit (Merck KGaA). Nucleic proteins were loaded on a 6 or $12 \%$ SDS-gel, resolved using SDS-PAGE and then transferred to a PVDF membrane (Merck KGaA). Membranes were blocked at $4^{\circ} \mathrm{C}$ with $5 \%$ BSA for $1 \mathrm{~h}$ and then incubated with a series of rabbit polyclonal antibodies, which included anti-ANP (1:5,000; Abcam; cat. no. ab189921), anti-H3K9ac (1:5,000; Abcam; cat. no. ab4441), anti-H3 (1:5,000; Abcam; cat. no. ab1791), anti- $\beta$-MHC (1:5,000; Abcam; cat. no. Ab207926) anti-BNP (1:1,000; Abcam; cat. no. ab239510), anti- $\beta$-actin (1:1,000; Abcam; cat. no. ab8226) and anti-PCAF (1:2,000; Abcam; cat. no. ab176316), anti-ERK (1:2,000; Cell Signaling
Technology, Inc.; cat. no. 4695) or anti phospho-(p-)ERK (1:2,000; Cell Signaling Technology, Inc.; cat. no. 4370); $\beta$-actin and $\mathrm{H} 3$ were served as an internal controls. All antibodies were diluted in Tris-buffered saline containing 5\% skimmed milk, and incubated with the membrane overnight at $4^{\circ} \mathrm{C}$. HRP-labeled goat anti-rabbit antibody $(1: 2,000$; Santa Cruz Biotechnology, Inc.; cat. no. sc2004) was used as the secondary antibody and incubated with the membrane at $4^{\circ} \mathrm{C}$ for $2 \mathrm{~h}$. The results were detected with enhanced chemiluminescence reagents (Wanleibio Co., Ltd.). Finally, membranes were scanned using a Bio-Rad image analyzer; and densitometry analysis was performed using Quantity One version 4.4 (Bio-Rad Laboratories, Inc.).

$R N A$ extraction and reverse transcription-quantitative (RT- $q)$ $P C R$. Cardiomyocytes were used for qPCR at a density of $2-3 \times 10^{6}$ cells/well. Total RNA was extracted from myocardial cells using an RNA Extraction kit (BioTeke Corporation), according to the manufacturer's protocol. Total RNA was then reverse transcribed into single-stranded cDNA using an AMV Reverse Transcription system, according to the manufacturer's protocol (Takara Bio, Inc.). cDNA was amplified using a SYBR Green dye kit and gene-specific primers (Takara Bio, Inc.). The primer sequences of $M E F 2 C$ and $\beta$-actin were: $M E F 2 C$ forward, 5'-CCTTTTCCTTTTCTGGGGACTTG TT-3' and reverse 5'-TGCCGCTGTGAGCCTCTATTTG-3'; and $\beta$-actin forward, 5'-CCTTTATCGGTATGGAGTCTG CG-3' and reverse, 5'-CTGACATGACGTTGTTGGCA-3'. $\beta$-actin was used as a standardized reference, and the $2^{-\Delta \Delta C q}$ method was used to determine relative gene expression (25).

Immunofluorescence. Cardiomyocytes were seeded into 6-well plates $\left(1 \times 10^{5}\right.$ cells/well) for $24 \mathrm{~h}$ and incubated with $50 \mu \mathrm{mol} / 1 \mathrm{AA}$ for $1 \mathrm{~h}$, then $10 \mu \mathrm{mol} / 1 \mathrm{U} 0126$ was added. After $48 \mathrm{~h}, 100 \mu \mathrm{mol} / 1 \mathrm{PE}$ was added. Subsequently, the cells were fixed with $4 \%$ paraformaldehyde for $15 \mathrm{~min}$ at room temperature (RT), treated with $0.3 \%$ Triton X-100 in PBS at RT for 20 min, and then incubated with 10\% goat serum (Solarbio Science \& Technology Co., Ltd.; cat. no. SL038) at $37^{\circ} \mathrm{C}$ for $30 \mathrm{~min}$. Subsequently, the cardiomyocytes were incubated at $4^{\circ} \mathrm{C}$ overnight with primary antibodies against $\alpha$-actin (1:100; ProteinTech Group, Inc.; cat. no. 23660-1-AP), H3K9ac (1:1,000 Abcam; cat. no. ab4441) and anti-PCAF (1:250; Abcam; cat. no. ab176316). The following morning, the cells were incubated at $37^{\circ} \mathrm{C}$ in the dark for $1 \mathrm{~h}$ with Alexa Fluor 594 goat anti-mouse $\mathrm{IgG}$ secondary antibody $(1: 1,000$; Thermo Fisher Scientific, Inc.; cat. no. A-11005) and Alexa Fluor 488 goat anti-rabbit IgG (1:200; Invitrogen; Thermo Fisher Scientific, Inc.; cat. no. A-11008) secondary antibody. Finally, the cardiomyocytes were counterstained with DAPI for $5 \mathrm{~min}$ at RT. All images were obtained using a confocal microscope (magnification, $\mathrm{x} 40$ ) with standardized imaging parameters. Finally, the images were quantified based on fluorescence using ImageJ 1.49 software (National Institutes of Health).

Co-immunoprecipitation (Co-IP). Co-IP was performed as described previously (26), using anti-phospho-(p-)ERK, anti-PCAF and anti-H3K9ac rabbit polyclonal antibodies with Dynabeads protein $\mathrm{G}$ magnetic beads (Invitrogen; Thermo Fisher Scientific, Inc.) for the immunoprecipitation and 

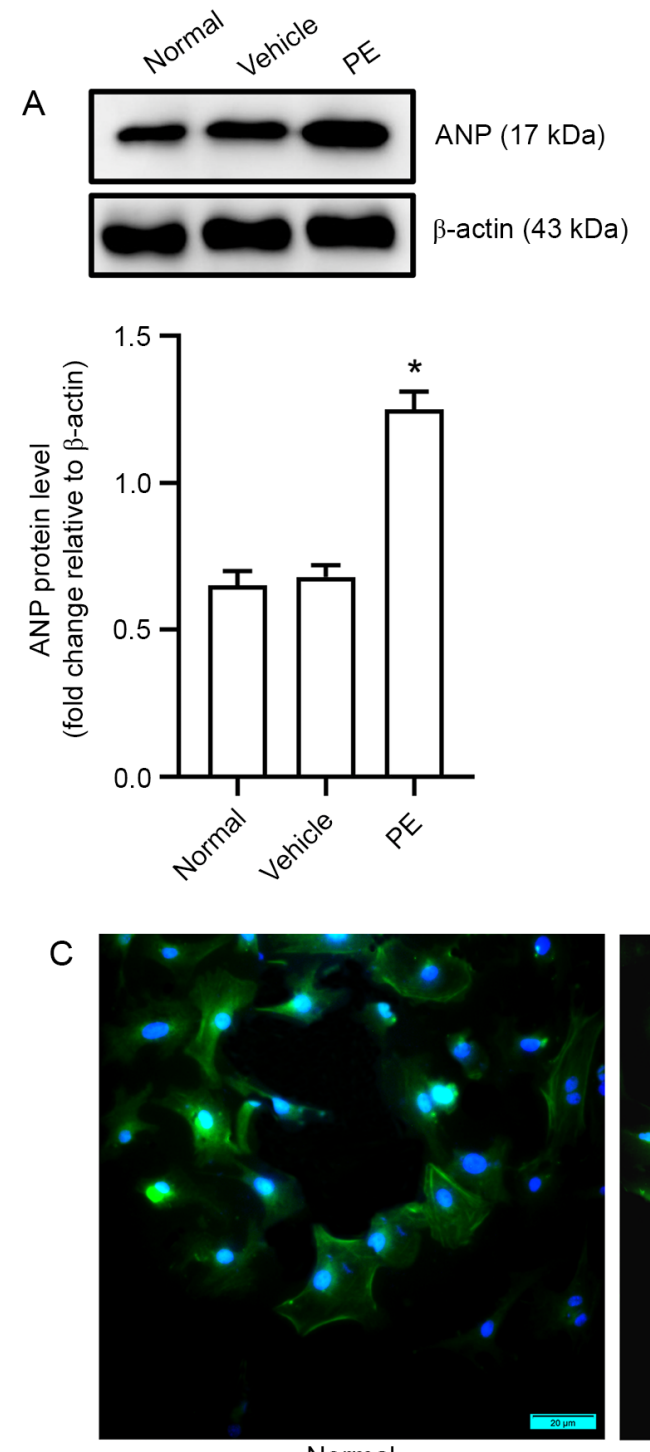

Normal
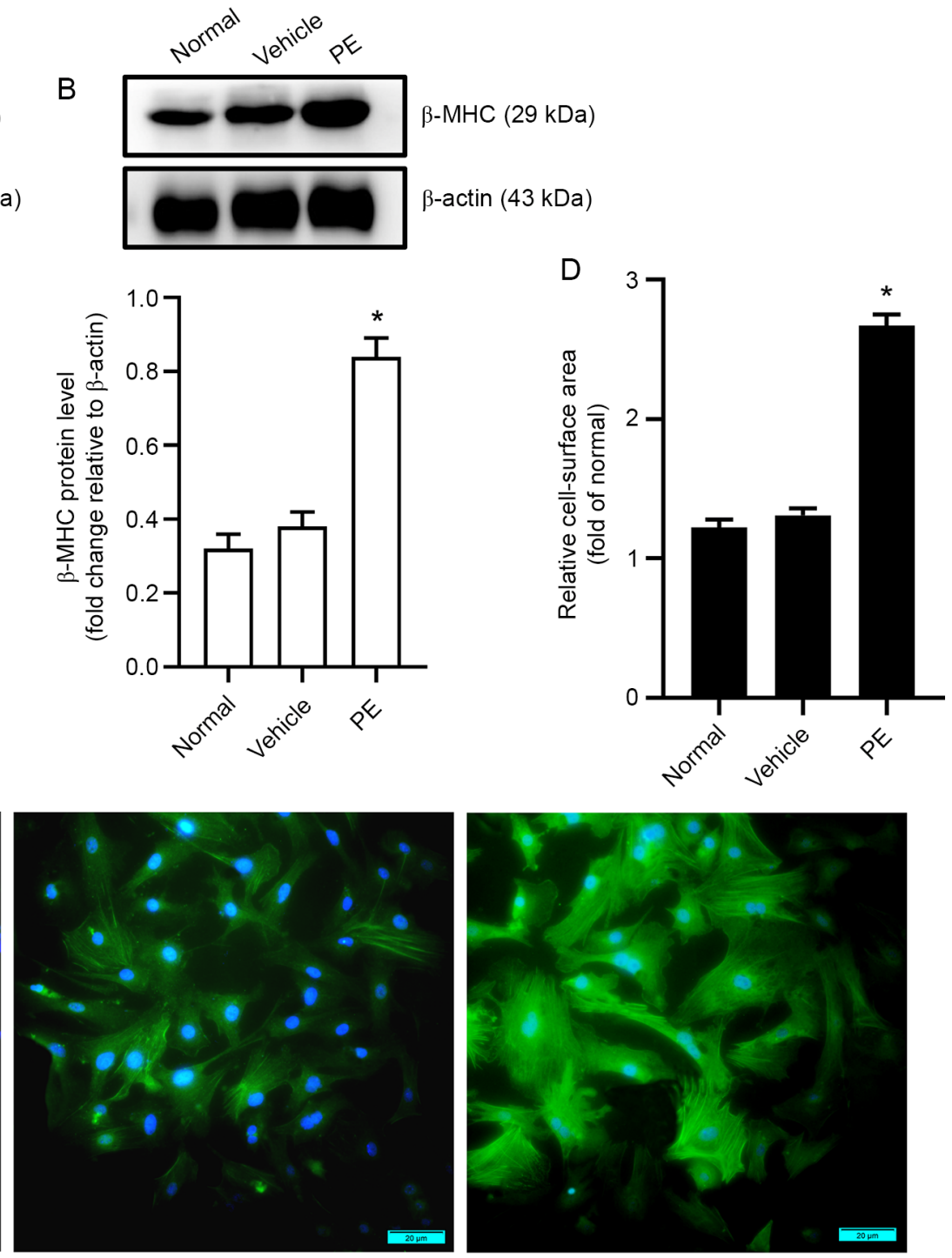

Vehicle

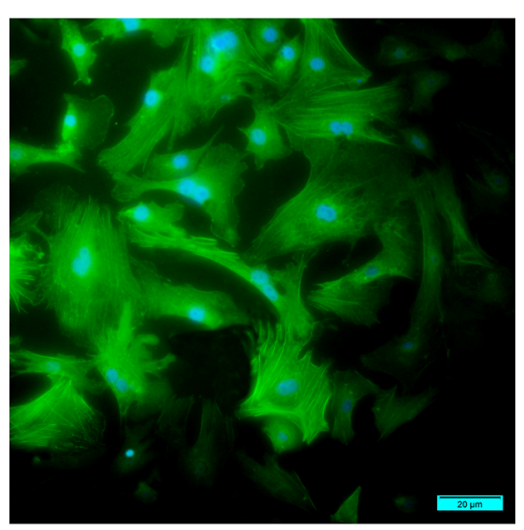

PE

Figure 1. Cardiomyocyte hypertrophy induced by PE. (A) Effects of PE on the expression levels of the myocardial hypertrophy biomarker ANP in primary cardiomyocytes from a neonatal mouse. (B) Effects of PE on the expression levels of the myocardial hypertrophy biomarker $\beta$-MHC in primary cardiomyocytes from a neonatal mouse. (C) Immunofluorescent staining analysis of the cell surface area in primary cardiomyocytes from a neonatal mouse. (D) Quantification of changes in the cell surface area in each group. Cells were treated with $100 \mu \mathrm{mol} / 1 \mathrm{PE}$ for $48 \mathrm{~h}$. $\mathrm{n}=6$. Scale bar, $20 \mu \mathrm{m}$. *P<0.05 vs. vehicle. PE, phenylephrine; ANP, atrial natriuretic peptide; $\beta$-MHC, $\beta$-myosin heavy chain; Vehicle, $100 \mu \mathrm{mol} / 1$ phenylephrine + equal volume of DMSO. for $48 \mathrm{~h}$.

western blotting of primary cardiomyocytes. First, the primary antibody was bound to Protein G magnetic beads (according to the manufacturer's protocol). Next, at $\mathrm{pH} 7.4$, a magnet along with $1 \%$ Triton X-100, 0.5\% NP-40, $20 \mathrm{mM}$ HEPES, $50 \mathrm{mM}$ $\mathrm{NaCl}$ and protease inhibitor (1:50; Beijing Solarbio Science \& Technology Co., Ltd.), were used to immunoprecipitate the target antigen (p-ERK) in the buffer. The sample was then washed three times with a lysis buffer. The immobilized protein complex was eluted, denatured in 5X SDS sample buffer at $95^{\circ} \mathrm{C}$ for $10 \mathrm{~min}$, and then subjected to western blotting analysis with anti-p-ERK (1:2,000; Cell Signaling Technology, Inc.; cat. no. 4370), anti-PCAF and anti-H3K9ac antibodies. IgG served as a negative control.

Chromatin immunoprecipitation (ChIP). ChIP was performed as described previously (26). Formaldehyde (1\%) was added to the homogenized cardiomyocytes to cross-link the
DNA-protein complex, and incubate at $37^{\circ} \mathrm{C}$ for $15 \mathrm{~min}$. ChIP determination was then performed using a specific kit (Merck KGaA). Next, the cross-linked complex DNA was sheared with ultrasound and precipitated with monoclonal antibodies (anti-MEF2C, 1:1,000; anti-H3K9ac, 1:2,000; and anti-PCAF, $1: 2,000)$ overnight at $4^{\circ} \mathrm{C}$. DNA purification kits (Merck $\mathrm{KGaA}$ ) were then used to extract the final DNA, according to the manufacturer's protocol. Normal mouse IgG (1:500; Sigma-Aldrich, Merck KGaA) was used as a negative control.

Statistical analysis. All experiments were repeated six time with six independent samples. All data are expressed as the mean \pm standard deviation. All statistical analyses were performed using SPSS version 18.0 (SPSS Inc.). Comparisons among multiple groups were analyzed using one-way ANOVA followed by Tukey's post-hoc test. $\mathrm{P}<0.05$ was considered to indicate a statistically significant difference. 
A
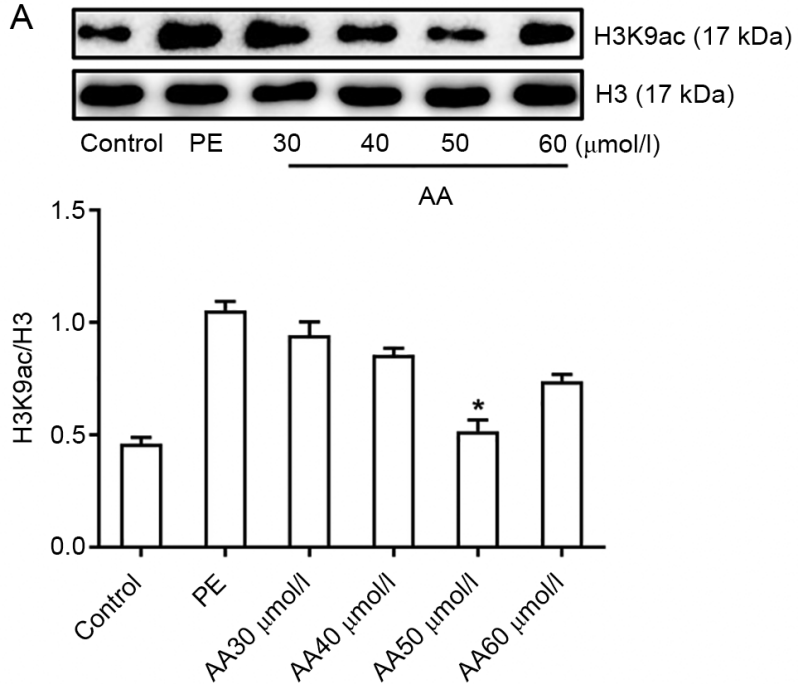

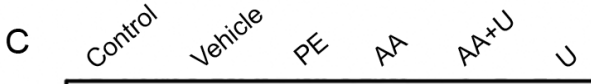

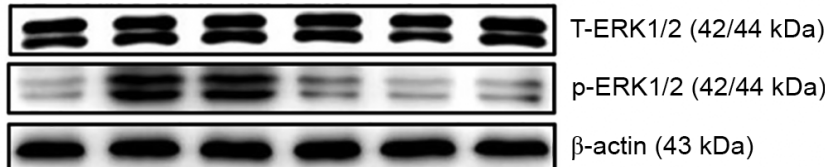

B

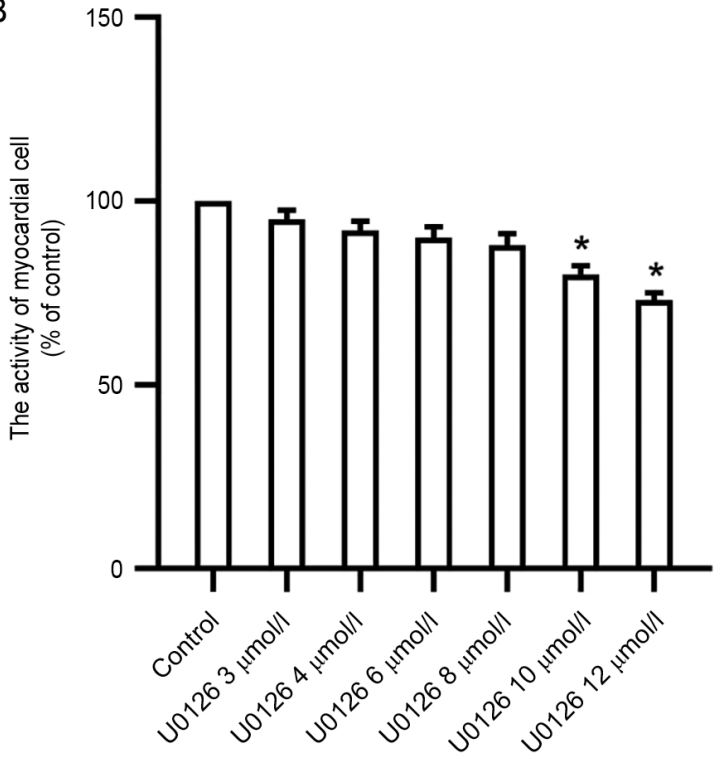

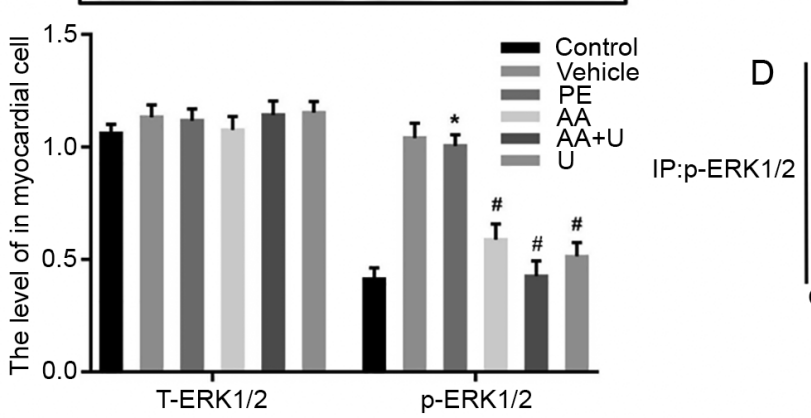

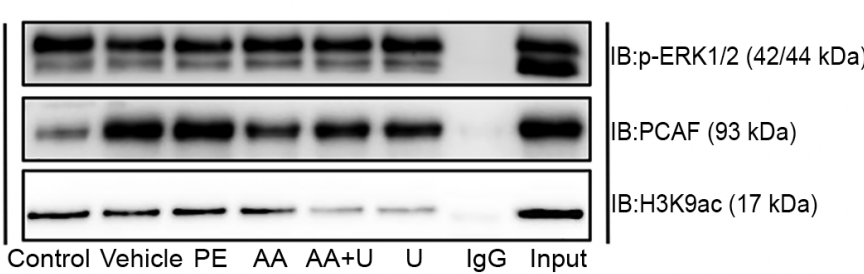

Figure 2. p-ERK1/2 interacted with PCAF and modified H3K9ac acetylation in hypertrophic cardiomyocytes induced by PE. (A) Different concentrations of AA $(30,40,50$ and $60 \mu \mathrm{mol} / 1)$ were used to identify the optimal concentration of AA; $50 \mu$ mol/1 was selected for subsequent experiments, based on the levels of histone H3K9ac. (B) Effects of different concentrations of the ERK inhibitor U0126 (2, 4, 6, 8 and 10 $\mu$ mol/l) on cell viability in neonatal mouse cardiomyocytes. (C) Expression of T-ERK1/2 and p-ERK1/2 in myocardial cells from neonatal mice. (D) Co-immunoprecipitation in cell lysates of mouse myocardial cells exposed to six different experimental conditions with anti-p-ERK1/2-protein G magnetic beads and IB with anti-PCAF, anti-H3K9ac or anti-p-ERK1/2 antibodies to evaluate protein expression. Input, positive control; IgG, negative control. $\mathrm{n}=6$. ${ }^{*} \mathrm{P}<0.05 \mathrm{vs}$. control group; ${ }^{\#} \mathrm{P}<0.05 \mathrm{vs}$. $\mathrm{PE}$ group. P-, phospho-; PCAF, P300/CBP-associated factor; PE, phenylephrine; H3K9ac, histone 3 acetylation K9; AA, anacardic acid; T-, total-; IB, immunoblotting; ERK, extracellular signal-regulated protein kinase; PE, $100 \mu \mathrm{mol} / 1$ phenylephrine for $48 \mathrm{~h}$; Vehicle, $100 \mu \mathrm{mol} / 1$ phenylephrine + equal volume of DMSO for $48 \mathrm{~h}$; AA, $50 \mu \mathrm{mol} / 1 \mathrm{AA}$ for $30 \mathrm{~min}+100 \mu \mathrm{mol} / 1$ phenylephrine for $48 \mathrm{~h}$; AA + U, $50 \mu \mathrm{mol} / 1 \mathrm{AA}+10 \mu \mathrm{mol} / 1 \mathrm{U} 0126 \mathrm{for} 30 \mathrm{~min}+100 \mu \mathrm{mol} / 1 \mathrm{phenylephrine}$ for $48 \mathrm{~h}$; U, $10 \mu \mathrm{mol} / 1 \mathrm{U} 0126$ for $30 \mathrm{~min}+100 \mu \mathrm{mol} / 1$ phenylephrine for $48 \mathrm{~h}$; Control, no drug.

\section{Results}

PE-induced cardiomyocyte hypertrophy in neonatal mice. In order to establish a model of PE-induced cardiomyocyte hypertrophy, first, the optimal PE exposure concentration (100 $\mu \mathrm{mol} / \mathrm{l})$ was determined based on a previous study (20). The treatment time of PE was $48 \mathrm{~h}$ in cultured myocardial cells, and the effects were determined using western blotting. Data arising from the western blotting experiments showed that the levels of biomarkers for myocardial hypertrophy (ANP and $\beta$-MHC) in the PE group were significantly higher than those in the vehicle group (Fig. 1A and B). Additionally, the cell-surface area was also assayed using immunofluorescence analysis. The results showed that myocardial cells in the PE group were significantly larger than those in the vehicle group (Fig. 1C and D). These data showed that a mouse model of PE-induced cardiomyocyte hypertrophy was successfully established.

p-ERK1/2 interacts with PCAF and altered H3K9ac acetylation in hypertrophic cardiomyocytes induced by $P E$. Studies have confirmed that the p-ERK1/2 signaling pathway plays an important role in pathological myocardial cell hypertrophy $(27,28)$. Thus, the effects of the ERK1/2 signaling pathway on the manner by which AA attenuates PCAF mediated-H3K9ac hyperacetylation in PE-induced hypertrophic cardiomyocytes was determined. First, according to the previous literature (21-24), the optimum concentration of the histone acetylase inhibitor AA was determined (50 $\mu \mathrm{mol} / \mathrm{l})$, as well as for the ERK inhibitor U0126 $(10 \mu \mathrm{mol} / \mathrm{l})$, in accordance with H3K9ac levels, and the viability of myocardial cells using western blotting and CCK-8 examination, respectively 

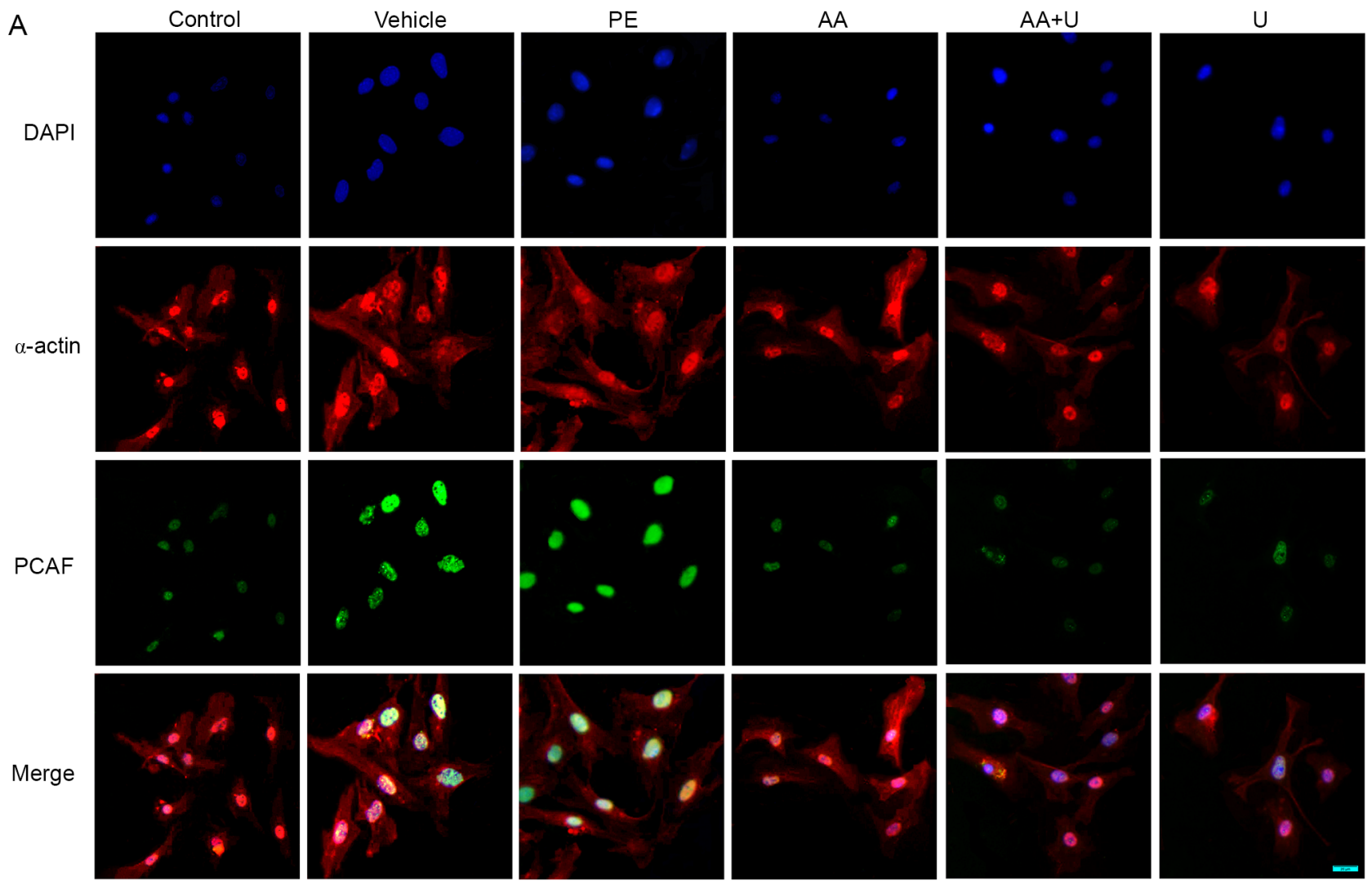

B

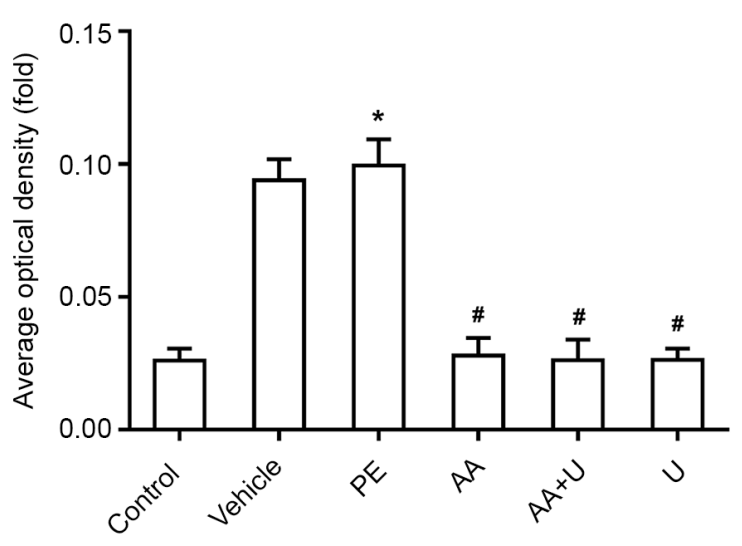

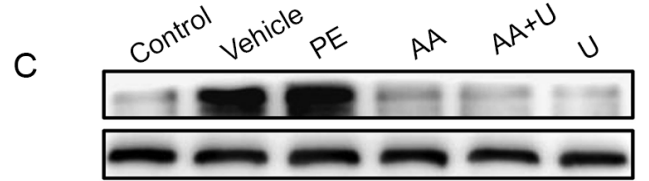

PCAF $(93 \mathrm{kDa})$ $\beta$-actin $(43 \mathrm{kDa})$

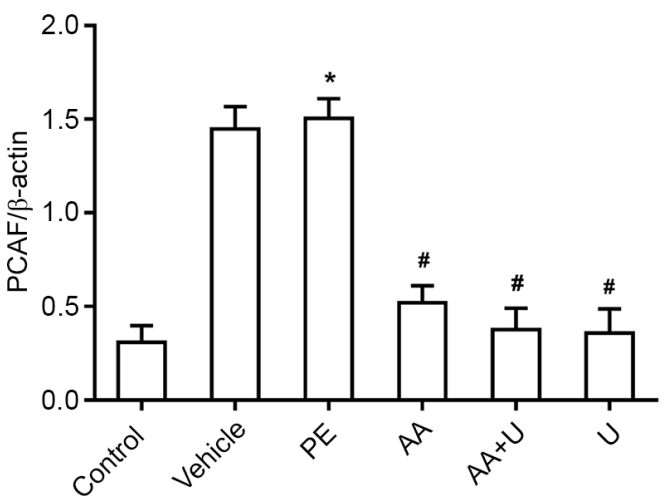

Figure 3. Effects of AA and U0126 on the expression of PCAF in PE-induced cardiomyocyte hypertrophy. (A) PCAF (green fluorescence) and $\alpha$-actin (red fluorescence), in combination with DAPI staining (blue fluorescence), in cardiomyocytes exposed to six different conditions. Scale bar, $20 \mu \mathrm{m}$. (B) Mean optical density of PCAF immunofluorescence in the six groups. (C) Western blotting of PCAF expression, showed PCAF levels were significantly higher in the hypertrophic cardiomyocytes induced by $\mathrm{PE}$, whereas AA and/or U0126 prevented this effect. $\mathrm{n}=6$. " $\mathrm{P}<0.05$ vs. control group; ${ }^{\#} \mathrm{P}<0.05$ vs. PE group. PCAF, P300/CBP-associated factor; PE, phenylephrine; AA, anacardic acid; PE, $100 \mu \mathrm{mol} / 1$ phenylephrine for $48 \mathrm{~h}$; Vehicle, $100 \mu \mathrm{mol} / 1 \mathrm{phenylephrine}+$ equal volume of DMSO for $48 \mathrm{~h}$; AA, $50 \mu \mathrm{mol} / 1 \mathrm{AA}$ for $30 \mathrm{~min}+100 \mu \mathrm{mol} / 1$ phenylephrine for $48 \mathrm{~h}$; AA $+\mathrm{U}, 50 \mu \mathrm{mol} / 1 \mathrm{AA}+10 \mu \mathrm{mol} / 1 \mathrm{U} 0126$ for $30 \mathrm{~min}+$ $100 \mu \mathrm{mol} / 1$ phenylephrine for $48 \mathrm{~h}$; U, $10 \mu \mathrm{mol} / 1 \mathrm{U} 0126$ for $30 \mathrm{~min}+100 \mu \mathrm{mol} / 1$ phenylephrine for $48 \mathrm{~h}$; Control, no drug.

(Fig. 2A and B). Additionally, the inhibitory activity of AA decreased as the concentration of AA was increased. As the concentration of the inhibitor increases, its inhibitory effect will gradually increase, but when the concentration of the inhibitor is higher than a certain level, its inhibitory effect will be weakened $(29,30)$. After hypertrophic cardiomyocytes had been treated with AA and/or U0126, the expression of total-(T-)ERK1/2 and p-ERK1/2 was determined by western blotting, and the results showed that the expression levels of p-ERK1/2 in the PE group were significantly higher than those in the control group. Additionally, it was also found that the HATs inhibitor AA, and the ERK inhibitor U0126 could ameliorate the increase in p-ERK1/2 levels induced by PE in primary cultured myocardial cells; however, the expression of T-ERK1/2 remained unchanged (Fig. 2C). In addition, our previous study found that an imbalance in the modification 


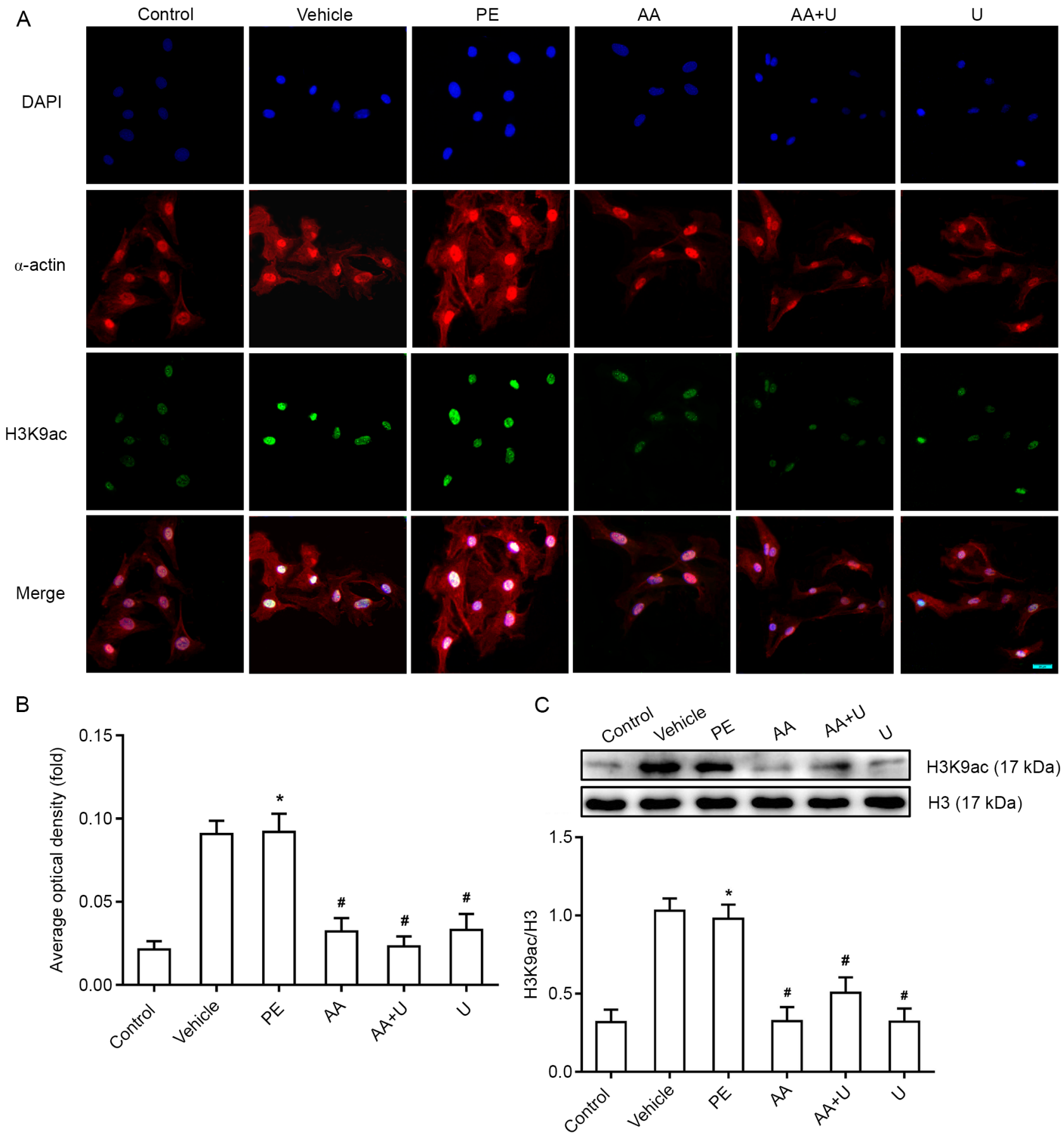

Figure 4. Acetylation levels of histone H3K9ac in mouse myocardial cells. (A) H3K9ac (green fluorescence) and $\alpha$-actin (red fluorescence), combined with DAPI staining (blue fluorescence), in cardiomyocytes exposed to six different conditions. Scale bar, $20 \mu \mathrm{m}$. (B) Mean optical density of H3K9ac immunofluorescence in the six groups. (C) Western blotting data showed that the levels of H3K9ac were significantly higher in the hypertrophic cardiomyocytes induced by PE, whereas AA and/or U0126 prevented this effect. $\mathrm{n}=6$. ${ }^{*} \mathrm{P}<0.05$ vs. control group; ${ }^{\#} \mathrm{P}<0.05$ vs. PE group. PCAF, P300/CBP-associated factor; PE, phenylephrine; AA, anacardic acid; PE, $100 \mu \mathrm{mol} / 1$ phenylephrine for $48 \mathrm{~h}$; Vehicle, $100 \mu \mathrm{mol} / 1$ phenylephrine + equal volume of DMSO for $48 \mathrm{~h}$; AA, $50 \mu \mathrm{mol} / 1 \mathrm{AA}$ for $30 \mathrm{~min}+100 \mu \mathrm{mol} / 1$ phenylephrine for $48 \mathrm{~h}$; AA $+\mathrm{U}, 50 \mu \mathrm{mol} / 1 \mathrm{AA}+10 \mu \mathrm{mol} / 1 \mathrm{U} 0126$ for $30 \mathrm{~min}+100 \mu$ mol/1 phenylephrine for $48 \mathrm{~h}$; U, $10 \mu \mathrm{mol} / 1 \mathrm{U} 0126$ for $30 \mathrm{~min}+100 \mu \mathrm{mol} / 1$ phenylephrine for $48 \mathrm{~h}$; Control, no drug; H3K9ac, histone 3 acetylation K9.

of histone H3K9ac, as mediated by PCAF, was involved in the pathological hypertrophy of myocardial cells (31). Next, whether the ERK1/2 signaling pathway interacted with PCAF in order to regulate the modification of histone H3K9ac acetylation and further enhance pathological cardiac hypertrophy was determined. Co-IP experiments were not used as an analytical method, but instead performed to verify the formation of a complex between the ERK1/2 signaling pathway and
PCAF mediated-H3K9ac acetylation, and it was successfully demonstrated that there was an interaction in the primary cultured myocardial cells. Collectively, these data indicated that the ERK1/2 signaling pathway may interact with PCAF mediated-H3K9ac acetylation (Fig. 2D).

Expression of PCAF in primary cultured myocardial cells. Our previous study showed that PCAF plays a critical role in 
A
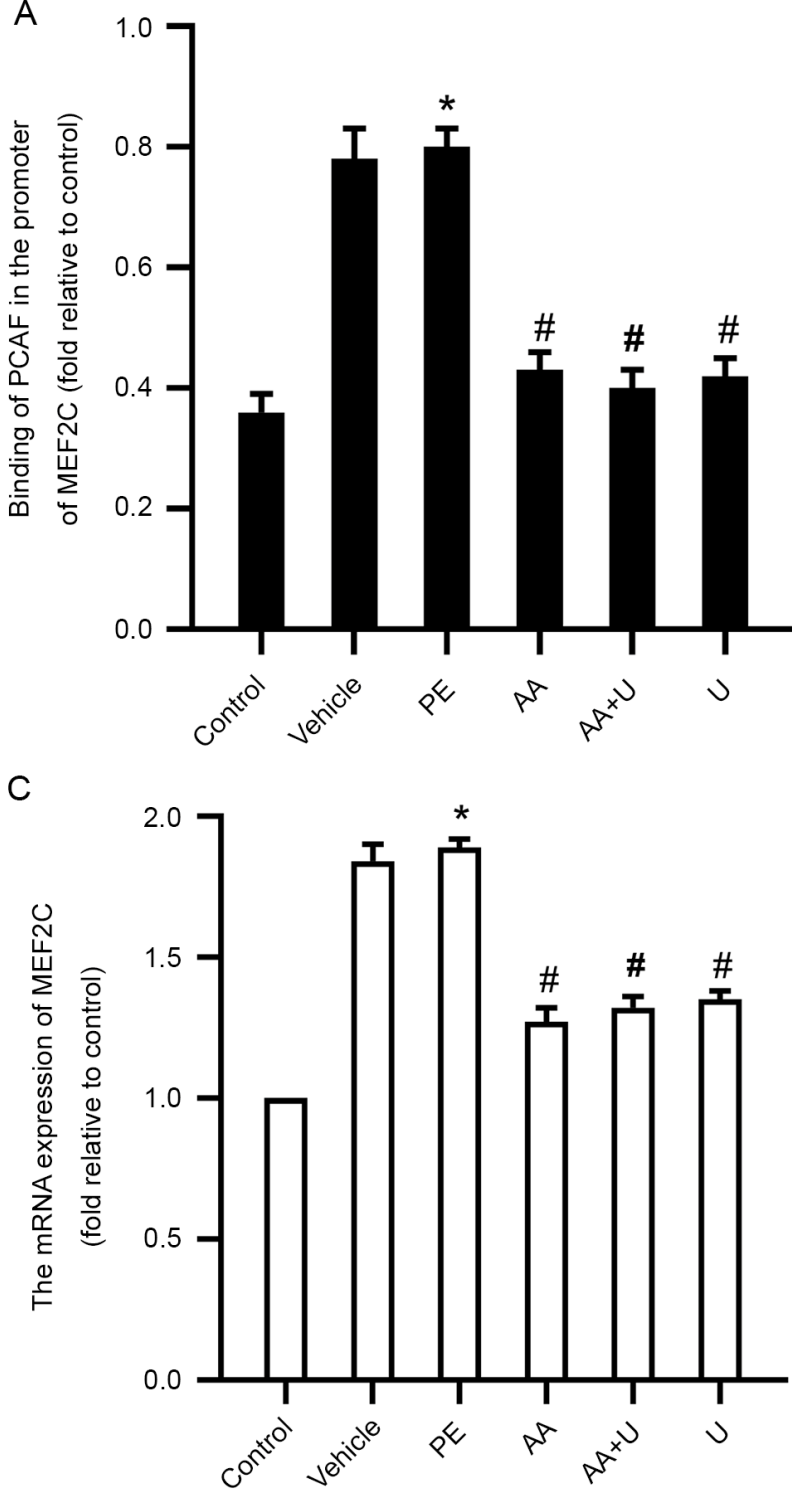

B
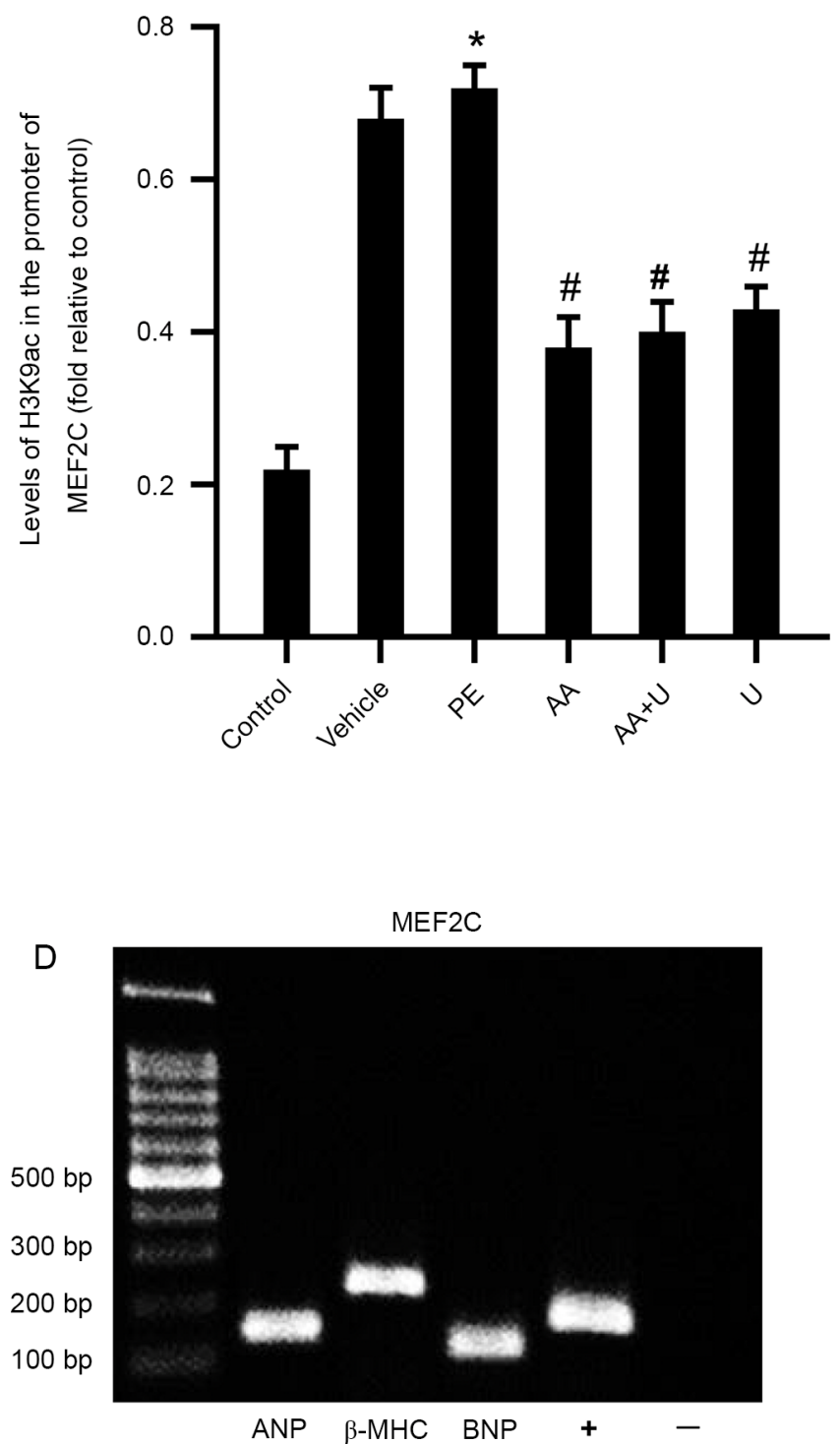

Figure 5. PCAF binding, acetylation levels of $\mathrm{H} 3 \mathrm{~K} 9 \mathrm{ac}$ in the $M E F 2 C$ promoter and the expression of $M E F 2 C$ in myocardial cells. (A) Binding of PCAF to the promoter in $M E F 2 C$ was assessed using ChIP-qPCR. (B) Acetylation levels of histone H3K9ac in the promoter of MEF2C were assessed using ChIP-qPCR. (C) mRNA expression of $M E F 2 C$ in cardiomyocytes exposed to six different conditions. (D) ChIP-qPCR data showed that the cardiac nuclear transcription factor $M E F 2 C$ could bind to the promoter of biomarker genes for cardiac hypertrophy $(A N P, B N P$ and $\beta-M H C) . \mathrm{n}=6 .{ }^{*} \mathrm{P}<0.05$ vs. control group; ${ }^{~} \mathrm{P}<0.05$ vs. $\mathrm{PE}$ group. PCAF, P300/CBP-associated factor; PE, phenylephrine; AA, anacardic acid; PE, $100 \mu \mathrm{mol} / 1$ phenylephrine for $48 \mathrm{~h}$; Vehicle, $100 \mu \mathrm{mol} / 1 \mathrm{phenyleph}$ rine + equal volume of DMSO for $48 \mathrm{~h}$; AA, $50 \mu \mathrm{mol} / 1 \mathrm{AA}$ for $30 \mathrm{~min}+100 \mu \mathrm{mol} / 1$ phenylephrine for $48 \mathrm{~h}$; AA + U, $50 \mu \mathrm{mol} / 1 \mathrm{AA}+10 \mu \mathrm{mol} / 1 \mathrm{U} 0126$ for $30 \mathrm{~min}+100 \mu \mathrm{mol} / 1$ phenylephrine for $48 \mathrm{~h} ; \mathrm{U}, 10 \mu \mathrm{mol} / 1 \mathrm{U} 0126$ for $30 \mathrm{~min}+100 \mu \mathrm{mol} / 1$ phenylephrine for $48 \mathrm{~h}$; Control, no drug; PCAF, P300/CBP-associated factor; PE, phenylephrine; H3K9ac, histone 3 acetylation K9; MEF2C, myocyte enhancer factor 2C; ChIP-qPCR, chromatin-immunoprecipitation-quantitative PCR; ANP, atrial natriuretic peptide; $\beta$-MHC, $\beta$-myosin heavy chain; BNP, brain natriuretic peptide.

pathological cardiac hypertrophy in a manner that is dependent on the modification of histone acetylation, and it was confirmed that $\mathrm{p}-\mathrm{ERK} 1 / 2$ could interact with PCAF mediated-H3K9ac acetylation (31). Thus, in the present study, the expression of PCAF was assessed by immunofluorescence and western blotting, and a notable increase in PCAF expression in hypertrophic cardiomyocytes was observed when induced by PE. In contrast, exposure to AA reversed the upregulation of PCAF in primary myocardial cells, as did the ERK inhibitor, U0126 (Fig. 3).

Levels of histone H3K9ac acetylation in primary cultured myocardial cells. Our previous study demonstrated that an imbalance in the modification of histone H3K9ac acetylation can result in pathological cardiac hypertrophy (32). In the present study, immunofluorescence and western blotting data showed that the levels of H3K9ac acetylation in the PE group were significantly higher than that in the control group. Additionally, it was shown that the HATs inhibitor AA, or the ERK inhibitor U0126, could downregulate the hyperacetylation of $\mathrm{H} 3 \mathrm{~K} 9 \mathrm{ac}$ induced by $\mathrm{PE}$ in primary myocardial cells (Fig. 4).

Overexpression of $M E F 2 C$ is mediated by $p$-ERK1/2-related H3K9ac hyperacetylation in myocardial cells treated with $P E . M E F 2 C$ is a nuclear transcription factor in cardiac cells that is involved in pathological cardiac hypertrophy 

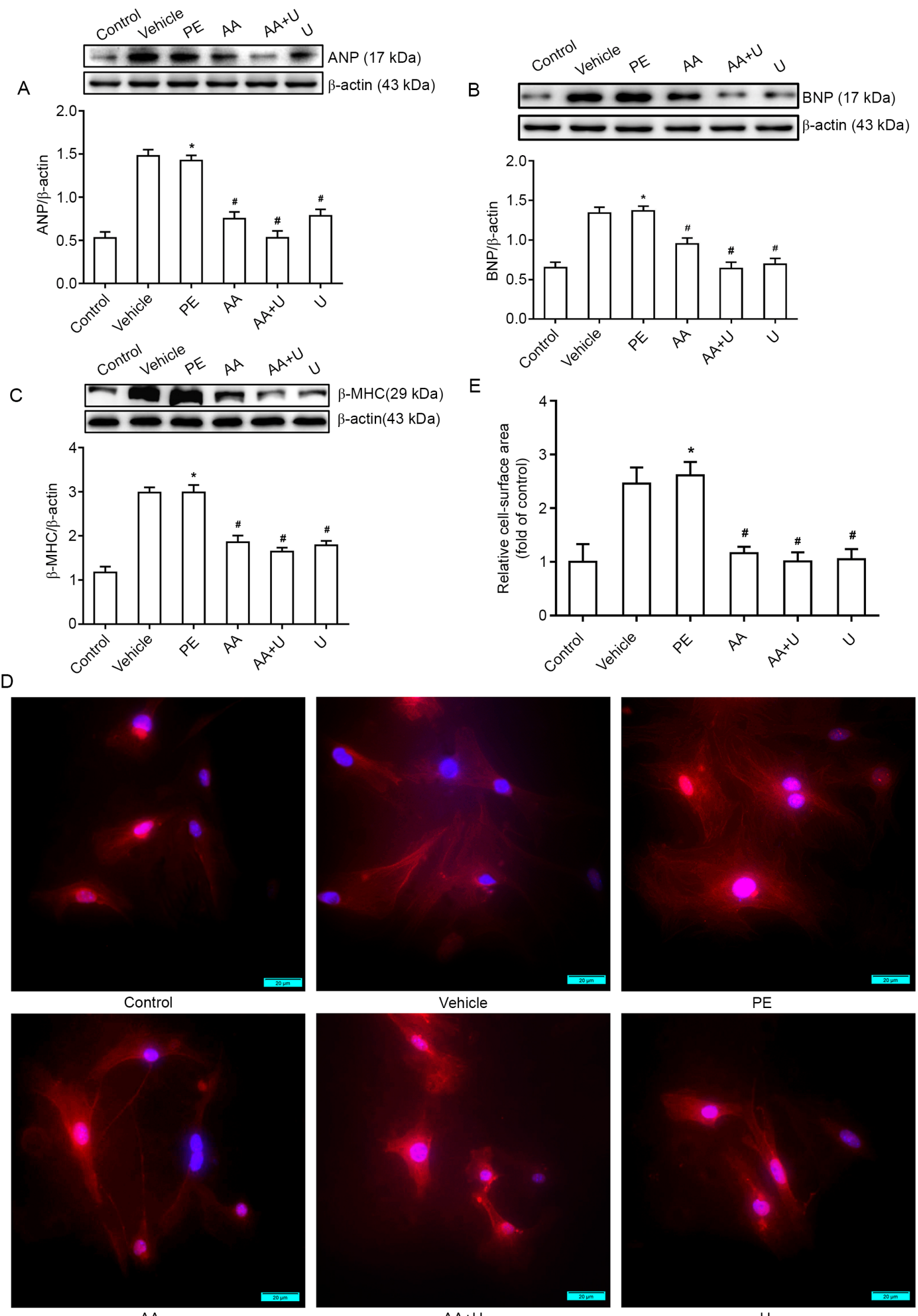

AA

$A A+U$

U

Figure 6. AA and U0126 alleviates PE-induced cardiomyocyte hypertrophy. (A-C) Western blotting data for cardiac hypertrophy biomarkers (ANP, BNP and $\beta-\mathrm{MHC}$ ). (D) Cell surface area was measured by immunofluorescence staining to demonstrate the hypertrophic responses in cardiomyocytes. (E) Quantification of the cell surface area of myocardial cells. Scale bar, $20 \mu \mathrm{m} . \mathrm{n}=6$. ${ }^{*} \mathrm{P}<0.05$ vs. control group; ${ }^{~} \mathrm{P}<0.05$ vs. PE group. PCAF, P300/CBP-associated factor; PE, phenylephrine; AA, anacardic acid; PE, $100 \mu \mathrm{mol} / 1$ phenylephrine for $48 \mathrm{~h}$; Vehicle, $100 \mu \mathrm{mol} / 1$ phenylephrine + equal volume of DMSO for $48 \mathrm{~h}$; AA, $50 \mu \mathrm{mol} / 1 \mathrm{AA}$ for $30 \mathrm{~min}+100 \mu \mathrm{mol} / 1$ phenylephrine for $48 \mathrm{~h}$; AA $+\mathrm{U}, 50 \mu \mathrm{mol} / 1 \mathrm{AA}+10 \mu \mathrm{mol} / 1 \mathrm{U} 0126$ for $30 \mathrm{~min}+100 \mu \mathrm{mol} / 1 \mathrm{phenylephrine} \mathrm{for} 48 \mathrm{~h}$; $\mathrm{U}, 10 \mu \mathrm{mol} / \mathrm{l} \mathrm{U} 0126$ for $30 \mathrm{~min}+100 \mu \mathrm{mol} / 1$ phenylephrine for $48 \mathrm{~h}$; Control, no drug; ANP, atrial natriuretic peptide; $\beta$-MHC, $\beta$-myosin heavy chain; BNP, brain natriuretic peptide; PE, phenylephrine. 


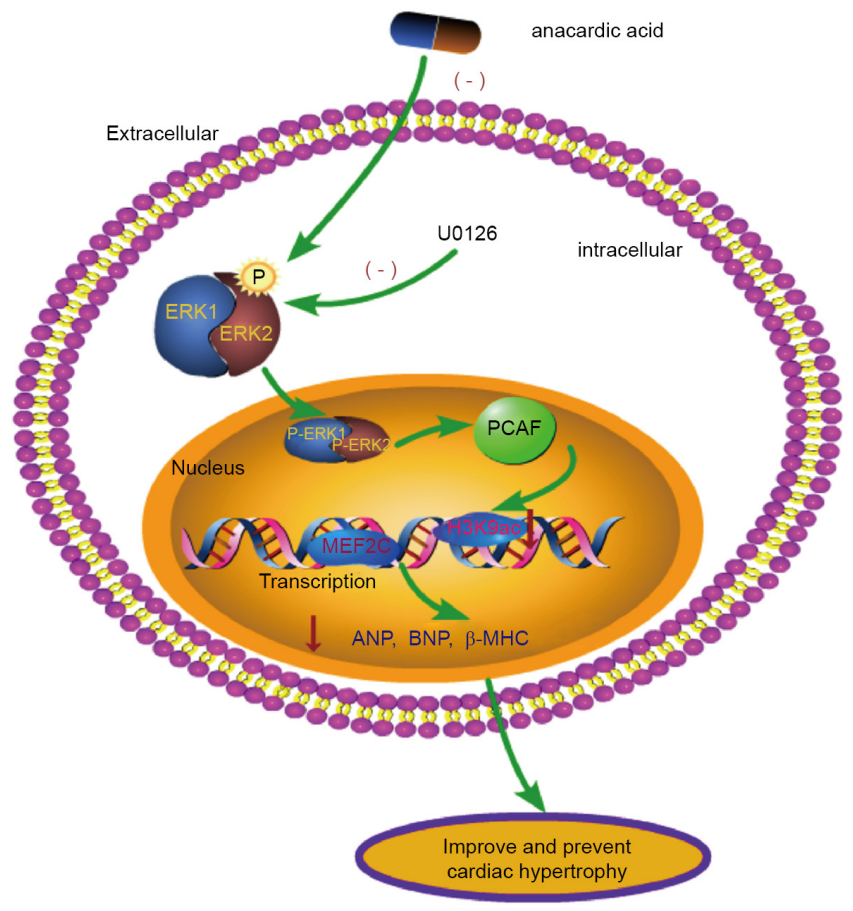

Figure 7. ERK $1 / 2$ cell signaling pathway. The interaction between p-ERK1/2 and PCAF leads to a reduction in $\mathrm{H} 3 \mathrm{~K} 9 \mathrm{ac}$ in PE-induced cardiomyocyte hypertrophy. p-, phospho-; PCAF, P300/CBP-associated factor; ANP, atrial natriuretic peptide; $\beta$-MHC, $\beta$-myosin heavy chain; $\mathrm{BNP}$, brain natriuretic peptide; $\mathrm{MEF} 2 \mathrm{C}$, myocyte enhancer factor 2C; $\mathrm{H} 3 \mathrm{~K} 9 \mathrm{ac}$, histone 3 acetylation $\mathrm{K}$; $\mathrm{PE}$, phenylephrine; ERK, extracellular signal-regulated protein kinase.

and several other cardiovascular diseases $(33,34)$. Therefore, the binding of PCAF and histone $\mathrm{H} 3 \mathrm{~K} 9 \mathrm{ac}$ acetylation in the promoter region of $M E F 2 C$ was assessed using ChIP-qPCR. The data showed that the levels of PCAF promoter binding of $M E F 2 C$ in the PE group was higher than that in the control group. Additionally, it was also found that the HATs inhibitor AA, and the ERK inhibitor U0126 downregulated the binding of PCAF to the promoter region of $M E F 2 C$. Meanwhile, the levels of histone $\mathrm{H} 3 \mathrm{~K} 9 \mathrm{ac}$ acetylation in the promoter region of $M E F 2 C$ was increased in the PE group. It was also evident that the HATs inhibitor AA, and the ERK inhibitor U0126, could attenuate the levels of histone H3K9ac acetylation in the promoter region of $M E F 2 C$ (Fig. 5A and B). The mRNA expression levels of the $M E F 2 C$ gene was determined using RT-qPCR, and the results showed there was a notable increase in gene expression in myocardial cells treated with PE. Exposure to AA or U0126 reduced the overexpression of $M E F 2 C$ mRNA in primary cultured myocardial cells treated with PE (Fig. 5C).

AA and U0126 reduce the levels of biomarkers of cardiac hypertrophy and attenuate hypertrophy in cardiomyocytes. To investigate the effects of $M E F 2 C$ on downstream genes associated with cardiac hypertrophy in cardiomyocytes, the regulatory relationship between $M E F 2 C$ and downstream genes associated with cardiac hypertrophy, including $A N P$, $B N P$ and $\beta-M H C$ were investigated. The binding affinity between $M E F 2 C$ and the promoters of $A N P, B N P$ and $\beta-M H C$, were detected by PCR following ChIP. The results showed that $M E F 2 C$ could bind to the promoters of $A N P, B N P$ and $\beta-M H C$
(Fig. 5D). These results indicate that $M E F 2 C$ is involved in regulating cardiac hypertrophy-related $A N P, B N P$ and $\beta-M H C$ gene expression. The levels of biomarkers of cardiac hypertrophy (ANP, BNP and $\beta$-MHC) at the protein level in the PE group were significantly higher than those in the control group. Additionally, it was found that AA and U0126 could reduce the increase in ANP, BNP and $\beta$-MHC levels in myocardial cells treated with PE (Fig. 6A, B and C). AA and U0126 could also significantly reduce the surface area of cardiomyocytes treated with PE (Fig. 6D and E).

\section{Discussion}

Myocardial hypertrophy is an adaptive response that is induced by a wide range of factors, including hemodynamic overload, myocardial injury and vascular disease. In its early stages, this disease is characterized by an increased volume of cardiomyocytes, although the number of these cells remains constant. Moreover, in an attempt to compensate for these effects, the myocardial contractility is enhanced; this way, the heart can maintain a normal ejection fraction $(35,36)$. These abnormalities further contribute to increased oxygen demand in the myocardial cells, which leads to insufficiency in terms of the blood supply and eventually results in myocardial fibrosis, arrhythmia and heart failure. However, the specific mechanisms underlying myocardial hypertrophy remain unclear. An increasing body of research is now investigating the epigenetic regulation of myocardial hypertrophy in an attempt to identify more effective treatments. Existing reports indicate that histone modification and DNA methylation are involved in the occurrence and development of myocardial hypertrophy $(37,38)$. The occurrence and development of cardiac hypertrophy is also accompanied by the abnormal activation of a large number of important signaling pathways $(5,39,40)$. Consequently, there is an increased level of interest in how key signaling pathways participate in the epigenetic regulation of cardiac hypertrophy $(41,42)$. Our previous studies found that an imbalance of histone acetylation modification is involved in PE-induced hypertrophy in cardiomyocytes, and that an HAT inhibitor, AA, can attenuate PE-induced cardiomyocyte hypertrophy (4); however, the relevant upstream signaling pathways have yet to be identified.

The development of cardiac hypertrophy is closely related to a variety of signaling pathways that interact with each other, for example, the Wnt signaling transduction pathway, the mitogen-activated protein kinase (MAPK) signaling transduction pathway and the microRNA signaling transduction pathway are all considered to be related to this process $(3,6,7,9)$. Of these, the MAPK signaling pathway has attracted significant attention $(43,44)$. In our previous study, it was confirmed that AA could attenuate pressure-overload cardiac hypertrophy through inhibition of histone acetylases (31), and the p38/MAPK and JNK/MAPK signaling pathways were involved in the attenuation of PE-induced cardiomyocyte hypertrophy in mice treated with AA $(20,45)$. MAPKs include ERK1/2, p38 and c-Jun N-terminal kinase (JNK) subfamilies; these pathways can transfer a variety of extracellular stimuli from the cell membrane to the nucleus and cause a range of biological effects, including differentiation, hypertrophy and apoptosis $(46,47)$. With regard to the MAPK signaling system, 
research has shown that ERK1/2 is mainly associated with cell growth, differentiation, development, proliferation, and a range of other physiological and pathological processes $(10,48)$. Other studies have shown that p38 and JNK can cause cell inflammation, apoptosis, growth, differentiation and stress responses $(49,50)$. Previous studies have also reported high expression levels of p-ERK in myocardial tissues from rats with pathological myocardial hypertrophy; furthermore, a reduction in the levels of p-ERK was effectively shown to improve myocardial hypertrophy (51). Phosphorylation of ERK at threonine 188, along with the activation of ERK5, has also been shown to be related to the pathological process of cardiomyocyte hypertrophy (41). Furthermore, as the first angiotensin receptor-enkephalin inhibitor, LCZ696 has been shown to attenuate cardiac remodeling by inhibiting the ERK signaling pathway in mice with pregnancy-associated cardiomyopathy (52). Collectively, these studies suggest that the ERK1/2 signaling pathway plays a critical role in the process of cardiomyocyte hypertrophy. Therefore, it was hypothesized that the ERK1/2 signaling pathway may be involved in the attenuation of PE-induced cardiomyocyte hypertrophy by AA. The activation of $\mathrm{p}$-ERK1/2 could phosphorylate downstream nuclear transcription factors and protein kinase substrates and regulate the occurrence and development of myocardial hypertrophy. In the present study, it was confirmed that the expression of p-ERK1/2 in the PE-treated group was significantly higher than that in the control group, although there was no change in the expression of T-ERK1/2; this suggested that phosphorylation of ERK1/2 may play an important regulatory role in PE-induced cardiomyocyte hypertrophy.

An increasing body of evidence has suggested that changes in signaling pathways may bring about epigenetic changes $(53,54)$. At present, research relating to histone modification focuses mainly on histone acetylation. As one of the subtypes closely related to cardiac hypertrophy, PCAF-HAT is known to acetylate histones and non-histones, activate chromatin and participate in pathological cardiac hypertrophy (55). However, PCAF-HAT does not bind DNA; rather PCAF-HAT is attracted to prime subsites by interacting with sequence-specific activators that mediate transcriptional activation (56). In the present study, it was confirmed that $\mathrm{p}$-ERK1/2 can combine with PCAF and histone H3K9ac to create a complex; this suggests that the p-ERK1/2 signaling pathway may participate in the modification of PCAF-mediated $\mathrm{H} 3 \mathrm{~K}$ 9ac acetylation to jointly regulate PE-induced cardiac hypertrophy. Certain studies have found that the ERK1/2 signaling pathway is involved in the overexpression of transcription factors that are related to cardiac development induced by alcohol exposure; these factors act by upregulating the levels of histone $\mathrm{H} 3$ acetylation (57). Class I histone deacetylases can inhibit cardiomyocyte hypertrophy by inhibiting the expression of genes encoding bispecific phosphatase 5 (a nucleophosphatase that negatively regulates hypertrophic signals through ERK1/2) (58). Together with the results of the present study, these data suggest that the regulatory mechanism underlying cardiac hypertrophy is diverse, and that its occurrence and development is a complex process.

Transcription factors are a group of protein molecules that can specifically bind to a specific sequence upstream of the 5 terminus of a gene; this ensures that the target gene is expressed in a specific time and space, and at a specific intensity (59). The analysis of transcription factors is a prerequisite and forms the basis for studying the regulation of gene expression. The overexpression of several cardiac core transcription factors (GATA4, $M E F 2 A$ and $M E F 2 C$ ) is an important factor that can lead to cardiac hypertrophy; these transcription factors are regulated by HATs $(4,33,60)$. In our previous study, it was shown that that the HAT inhibitor, AA, can downregulate the transcriptional activation of GATA4 by inhibiting P300 and PCAF, and thus attenuate the myocardial hypertrophy caused by alcohol exposure during pregnancy in fetal mice (61). Based on this finding, it was hypothesized that PCAF-mediated changes in the transcriptional activity of GATA4 were not the only regulatory factors that lead to cardiac hypertrophy. Indeed, $M E F 2 C$ is involved in heart development at various stages and shows high DNA binding activity in cardiomyocytes (62). Changes in the transcription levels of transcriptional factors that lie upstream of cardiac hypertrophy are different to the genes that lie downstream. In the present study, ChIP-PCR results showed that $M E F 2 C$ binds to the promoters of $A N P, B N P$ and $\beta$-MHC, whereas an ERK inhibitor (U0126) and a HAT inhibitor (AA) could inhibit the transcriptional activity of $M E F 2 C$, and therefore reduce the expression of ANP, BNP and $\beta$-MHC in the myocardial cells of mice. This further suggests that the involvement of the ERK signaling pathway in the modification of histone acetylation is strongly associated with the occurrence and development of pathological cardiac hypertrophy.

In conclusion, cardiac development is a delicate and complex process and is closely related to gene transcription and modification. In the present study, it was shown that the ERK1/2 signaling pathway interacts with PCAF to modify H3K9ac hyperacetylation and that this process plays a significant role in the cardiomyocyte hypertrophy induced by PE (Fig. 7). PE induces phosphorylation of ERK1/2 to generate p-ERK1/2. p-ERK1/2 upregulates expression of PCAF leading to acetylation of $\mathrm{H} 3 \mathrm{~K} 9 \mathrm{ac}$, thereby increasing the binding of $\mathrm{MEF} 2 \mathrm{C}$ in the promoter region. The increased production of the myocardial hypertrophy factors ANP, BNP and $\beta$-MHC cause cardiomyocyte hypertrophy. These findings may lead to the development of novel interventional targets and candidate drugs for the clinical prevention and treatment of myocardial hypertrophy.

\section{Acknowledgements}

Not applicable.

\section{Funding}

This work was supported by the National Natural Science Foundation of China (grant nos. 82060046 and 81560040).

\section{Availability of data and materials}

All data generated or analyzed during the present study are included in the published article.

\section{Authors' contributions}

QM drafted the manuscript. BHP and CP conceived and designed the study. SQW and QM performed the experiments 
and confirmed the authenticity of all the raw data. XML and LXH collected the experimental results. HTZ analyzed the data. All authors have read and approved the final manuscript.

\section{Ethics approval and consent to participate}

All animal experiments were approved by the Animal Protection and Use Committee of Zunyi Medical University (Zunyi, China), and complied with Directive 2010/63/EU of the European Parliament.

\section{Patient consent for publication}

Not applicable.

\section{Competing interests}

The authors declare that they have no competing interests.

\section{References}

1. Degoricija V, Trbušić M, Potočnjak I, Radulović $B$, Terešak SD, Pregartner G, Berghold A, Tiran B and Frank S: Acute heart failure developed as worsening of chronic heart failure is associated with increased mortality compared to de novo cases. Sci Rep 8: 9587, 2018.

2. Yu B, Zhao Y, Zhang H, Xie D, Nie W and Shi K: Inhibition of microRNA-143-3p attenuates myocardial hypertrophy by inhibiting inflammatory response. Cell Biol Int 42: 1584-1593, 2018

3. Wehbe N, Nasser SA, Pintus G, Badran A, Eid AH and Baydoun E: MicroRNAs in cardiac hypertrophy. Int J Mol Sci 20: 4714, 2019

4. Peng C, Luo X, Li S and Sun H: Phenylephrine-induced cardiac hypertrophy is attenuated by a histone acetylase inhibitor anacardic acid in mice. Mol Biosyst 13: 714-724, 2017.

5. Gao W, Guo N, Zhao S, Chen Z, Zhang W, Yan F, Liao H and Chi K: Carboxypeptidase A4 promotes cardiomyocyte hypertrophy through activating PI3K-AKT-mTOR signaling. Biosci Rep 40: BSR20200669, 2020.

6. Gai Z, Wang Y, Tian L, Gong G and Zhao J: Whole genome level analysis of the Wnt and DIX gene families in mice and their coordination relationship in regulating cardiac hypertrophy. Front Genet 12: 608936, 2021.

7. Siti HN, Jalil J, Asmadi AY and Kamisah Y: Rutin modulates MAPK pathway differently from Quercetin in angiotensin II-Induced H9c2 cardiomyocyte hypertrophy. Int J Mol Sci 22: 5063, 2021.

8. Bogdanova E, Beresneva O, Galkina O, Zubina I, Ivanova G, Parastaeva M, Semenova N and Dobronravov V: Myocardial hypertrophy and fibrosis are associated with cardiomyocyte Beta-Catenin and TRPC6/Calcineurin/NFAT signaling in spontaneously hypertensive rats with 5/6 Nephrectomy. Int J Mol Sci 22: 4645, 2021.

9. Tamura S, Marunouchi T and Tanonaka K: Heat-shock protein 90 modulates cardiac ventricular hypertrophy via activation of MAPK pathway. J Mol Cell Cardiol 127: 134-142, 2019.

10. Hu B, Song JT, Ji XF, Liu ZQ, Cong ML and Liu DX: Sodium Ferulate protects against angiotensin II-Induced cardiac hypertrophy in mice by regulating the MAPK/ERK and JNK Pathways. Biomed Res Int 2017: 3754942, 2017.

11. Yan ZP, Li JT, Zeng N and Ni GX: Role of extracellular signal-regulated kinase 1/2 signaling underlying cardiac hypertrophy. Cardiol J 28: 473-482, 2021.

12. Gu J, Hu W, Song ZP, Chen YG, Zhang DD and Wang CQ: Rapamycin inhibits cardiac hypertrophy by promoting autophagy via the MEK/ERK/Beclin-1 pathway. Front Physiol 7: 104, 2016.

13. Huang Y, Wu L, Wu J, Li Y and Hou L: Cellular FLICE-like inhibitory protein protects against cardiac hypertrophy by blocking ASK1/p38signaling in mice. Mol Cell Biochem 397: 87-95, 2014.

14. Zhou J, Gao J, Zhang X, Liu Y, Gu S, Zhang X, An X, Yan J, Xin Y and Su P: MicroRNA-340-5p functions downstream of cardiotrophin-1 to regulate cardiac eccentric hypertrophy and heart failure via target gene dystrophin. Int Heart J 56: 454-458, 2015.
15. Li B, Wang X, Yu M, Yang P and Wang W: G6PD, bond by miR-24, regulates mitochondrial dysfunction and oxidative stress in phenylephrine-induced hypertrophic cardiomyocytes. Life Sci 260: 118378, 2020.

16. Melchert RB, Liu H, Granberry MC and Kennedy RH: Lovastatin inhibits phenylephrine-induced ERK activation and growth of cardiac. Cardiovasc Toxicol 1: 237-252, 2001.

17. Zhong L, Chiusa M, Cadar AG, Lin A, Samaras S, Davidson JM and Lim CC: Targeted inhibition of ANKRD1 disrupts sarcomeric ERK-GATA4 signal transduction and abrogates phenylephrine-induced cardiomyocyte hypertrophy. Cardiovasc Res 106: 261-271, 2015.

18. Schreckenberg R, Taimor G, Piper HM and Schlüter KD: Inhibition of $\mathrm{Ca} 2+-$ dependent PKC isoforms unmasks ERK-dependent hypertrophic growth evoked by phenylephrine in adult ventricular cardiomyocytes. Cardiovasc Res 63: 553-560, 2004.

19. EUR-Lex: Directive 2010/63/EU of the European Parliament and of the Council of 22 September 2010 on the protection of animals used for scientific purposes. Official J European Union 53: L 276/33-L 276/79, 2010.

20. Peng BH, Peng C, Huang LX, Luo XM and Han X: The roles of P38 MAPK in the process of anacardic acid attenuating mouse cardiomyocyte hypertrophy induced by phenylephrine. Chin J Pathophys 36: 200-205, 2020.

21. Yin Y, Guan Y, Duan J, Wei G, Zhu Y, Quan W, Guo C, Zhou D, Wang Y, Xi M and Wen A: Cardioprotective effect of Danshensu against myocardial ischemia/reperfusion injury and inhibits apoptosis of H9c2 cardiomyocytes via Akt and ERK1/2 phosphorylation. Eur J Pharmacol 699: 219-226, 2013.

22. Zhao Q, Zhang X, Cai H, Zhang P, Kong D, Ge X, Du M, Liang R and Dong W: Anticancer effects of plant derived anacardic acid on human breast cancer MDA-MB-231 cells. Am J Transl Res 10: 2424-2434, 2018.

23. Li Q, Li ZM, Sun SY, Wang LP, Wang PX, Guo Z, Yang HW, Ye JT, Lu J and Liu PQ: PARP1 interacts with HMGB1 and promotes its nuclear export in pathological myocardial hypertrophy. Acta Pharmacol Sin 40: 589-598, 2019.

24. Frias MA, Rebsamen MC, Gerber-Wicht $\mathrm{C}$ and Lang U: Prostaglandin E2 activates Stat3 in neonatal rat ventricular cardiomyocytes: A role in cardiac hypertrophy. Cardiovasc Res 73: 57-65, 2007.

25. Livak KJ and Schmittgen TD: Analysis of relative gene expression data using real-time quantitative PCR and the 2(-Delta Delta C(T)) method. Methods 25: 402-408, 2001.

26. Peng B, Han X, Peng C, Luo X, Deng L and Huang L: G9a-dependent histone H3K9me3 hypomethylation promotes overexpression of cardiomyogenesis-related genes in foetal mice. J Cell Mol Med 24: 1036-1045, 2020.

27. Ren J, Zhang N, Liao H, Chen S, Xu L, Li J, Yang Z, Deng W and Tang Q: Caffeic acid phenethyl ester attenuates pathological cardiac hypertrophy by regulation of MEK/ERK signaling pathway in vivo and vitro. Life Sci 181: 53-61, 2017.

28. Saleem N, Prasad A and Goswami SK: Apocynin prevents isoproterenol-induced cardiac hypertrophy in rat. Mol Cell Biochem 445: 79-88, 2018.

29. Önal B, Özen D, Demir B, Gezen Ak D, Dursun E, Demir C, Akkan AG and Özyazgan S: The anti-inflammatory effects of Anacardic acid on a TNF- $\alpha$-Induced human saphenous vein endothelial cell culture model. Curr Pharm Biotechnol 21: 710-719, 2020.

30. Lee MJ, Tsai YJ, Lin MY, You HL, Kalyanam N, Ho CT and Pan MH: Calebin-A induced death of malignant peripheral nerve sheath tumor cells by activation of histone acetyltransferase. Phytomedicine 57: 377-384, 2019.

31. Li S, Peng B, Luo X, Sun H and Peng C: Anacardic acid attenuates pressure-overload cardiac hypertrophy through inhibiting histone acetylases. J Cell Mol Med 23: 2744-2752, 2019.

32. Luo XM, Che JL, Liu SR, Long S, Zhao PX, Xu P, Wei Y and Peng C: The effects of histone acetylation modification on cardiac hypertrophy induced by two different modeling methods in mice. J Clin Cardiol 33: 1106-1110, 2017.

33. Zhang G and Ni X: Knockdown of TUG1 rescues cardiomyocyte hypertrophy through targeting the miR-497/MEF2C axis. Open Life Sci 16: 242-251, 2021.

34. Khajehlandi M, Bolboli L, Siahkuhian M, Rami M, Tabandeh M, Khoramipour K and Suzuki K: Endurance training regulates expression of some angiogenesis-related genes in cardiac tissue of experimentally induced diabetic rats. Biomolecules 11: 498, 2021 . 
35. Wang HN, Li JL, Xu T, Yao HQ, Chen GH and Hu J: Effects of Sirt3 autophagy and resveratrol activation on myocardial hypertrophy and energy metabolism. Mol Med Rep 22: 1342-1350, 2020.

36. Ding J, Liu S, Qian W, Wang J, Chu C, Wang J, Li K, Yu Y, $\mathrm{Xu} \mathrm{G}$, Mao Z, et al: Swietenine extracted from Swietenia relieves myocardial hypertrophy induced by isoprenaline in mice. Environ Toxicol 35: 1343-1351, 2020.

37. Zhang LX, Du J, Zhao YT, Wang J, Zhang S, Dubielecka PM, Wei L, Zhuang S, Qin G, Chin YE and Zhao TC: Transgenic overexpression of active HDAC4 in the heart attenuates cardiac function and exacerbates remodeling in infarcted myocardium. J Appl Physiol 125: 1968-1978, 2018.

38. Stenzig J, Schneeberger Y, Löser A, Peters BS, Schaefer A, Zhao RR, Ng SL, Höppner G, Geertz B, Hirt MN, et al: Pharmacological inhibition of DNA methylation attenuates pressure overload-induced cardiac hypertrophy in rats. J Mol Cell Cardiol 120: 53-63, 2018.

39. Lin L, Xu W, Li Y, Zhu P, Yuan W, Liu M, Shi Y, Chen Y, Liang J, Chen J, et al: Pygol regulates pathological cardiac hypertrophy via a $\beta$-catenin-dependent mechanism. Am J Physiol Heart Circ Physiol 320: H1634-H1645, 2021.

40. Kuwabara Y, Horie T, Baba O, Watanabe S, Nishiga M, Usami S, Izuhara M, Nakao T, Nishino T, Otsu K, et al: MicroRNA-451 exacerbates lipotoxicity in cardiac myocytes and high-fat diet-induced cardiac hypertrophy in mice through suppression of the LKB1/AMPK pathway. Circ Res 116: 279-288, 2015.

41. Gallo S, Vitacolonna A, Bonzano A, Comoglio P and Crepaldi T: ERK: A key player in the pathophysiology of cardiac hypertrophy. Int J Mol Sci 20: 2164, 2019.

42. Breitenbach T, Lorenz K and Dandekar T: How to steer and control ERK and the ERK signaling cascade exemplified by looking at cardiac insufficiency. Int J Mol Sci 20: 2179, 2019

43. Liu R and Molkentin JD: Regulation of cardiac hypertrophy and remodeling through the dual-specificity MAPK phosphatases (DUSPs). J Mol Cell Cardio 101: 44-49, 2016.

44. Zhang Y, Cui Y, Dai S, Deng W, Wang H, Qin W, Yang H, Liu H, Yue J, Wu D, et al: Isorhynchophylline enhances Nrf2 and inhibits MAPK pathway in cardiac hypertrophy. Naunyn Schmiedebergs Arch Pharmacol 393: 203-212, 2020.

45. Peng BH: Role of JNK/MAPK signaling-dependent regulation of histone acetylation on the attenuation of anacardic acid for cardiomyocyte hypertrophy induced by phenylephrine (unpublished PhD thesis). Zunyi Medical University, 2020.

46. Ba L, Gao J, Chen Y, Qi H, Dong C, Pan H, Zhang Q, Shi P, Song C, Guan X, et al: Allicin attenuates pathological cardiac hypertrophy by inhibiting autophagy via activation of $\mathrm{PI} 3 \mathrm{~K} / \mathrm{Akt} / \mathrm{mTOR}$ and MAPK/ERK/mTOR signaling pathways Phytomedicine 58: 152765, 2019.

47. Kim MJ, Im MA, Lee JS, Mun JY, Kim DH, Gu A and Kim IS Effect of S100A8 and S100A9 on expressions of cytokine and skin barrier protein in human keratinocytes. Mol Med Rep 20: 2476-2483, 2019

48. Sun Y, Liu WZ, Liu T, Feng X, Yang N and Zhou HF: Signaling pathway of MAPK/ERK in cell proliferation, differentiation, migration, senescence and apoptosis. J Recept Signal Transduct Res 35: 600-604, 2015

49. Gentile MT, Russo R, Pastorino O, Cioffi S, Barbieri F, Illingworth EA, Grieco M, Chambery A and Colucci-D'Amato L: Ruta graveolens water extract inhibits cell-cell network formation in human umbilical endothelial cells via MEK-ERK1/2 pathway. Exp Cell Res 64: 50-58, 2018.
50. Dai X, Song R and Xiong Y: The expression of ERK and JNK in patients with an endemic osteochondropathy, Kashin-Beck disease. Exp Cell Res 359: 337-341, 2017.

51. Cipolletta E, Rusciano MR, Maione AS, Santulli G, Sorriento D, Del Giudice C, Ciccarelli M, Franco A, Crola C, Campiglia P, et al: Targeting the CaMKII/ERK interaction in the heart prevents cardiac hypertrophy. PLoS One 10: e0130477, 2015.

52. Wang Y, Guo Z, Gao Y, Liang P, Shan Y and He J: Angiotensin II receptor blocker LCZ696 attenuates cardiac remodeling through the inhibition of the ERK signaling pathway in mice with pregnancy-associated cardiomyopathy. Cell Biosci 9: 86, 2019.

53. Thienpont B, Aronsen JM, Robinson EL, Okkenhaug H, Loche E, Ferrini A, Brien P, Alkass K, Tomasso A, Agrawal A, et al: The H3K9 dimethyltransferases EHMT1/2 protect against pathological cardiac hypertrophy. J Clin Invest 127: 335-348, 2017.

54. Xing S, Tian JZ, Yang SH, Huang XT, Ding YF, Lu QY, Yang JS and Yang WJ: Setd4 controlled quiescent $\mathrm{c}-\mathrm{Kit}^{+}$cells contribute to cardiac neovascularization of capillaries beyond activation. Sci Rep 11: 11603, 2021

55. Wei J, Joshi S, Speransky S, Crowley C, Jayathilaka N, Lei X, Wu Y, Gai D, Jain S, Hoosien M, et al: Reversal of pathological cardiac hypertrophy via the MEF2-coregulator interface. JCI Insight 2: e91068, 2017.

56. Marmorstein R and Zhou MM: Writers and readers of histone acetylation: Structure, mechanism, and inhibition. Cold Spring Harb Perspect Biol 6: a018762, 2014.

57. Gao W, Pan B, Liu L, Huang X, Liu Z and Tian J: Alcohol exposure increases the expression of cardiac transcription factors through ERK1/2-mediated histone3 hyperacetylation in H9c2 cells. Biochem Biophys Res Commun 466: 670-675, 2015.

58. Ferguson BS, Harrison BC, Jeong MY, Reid BG, Wempe MF, Wagner FF, Holson EB and McKinsey TA: Signal-dependent repression of DUSP5 by class I HDACs controls nuclear ERK activity and cardiomyocyte hypertrophy. Proc Natl Acad Sci USA 110: 9806-9811, 2013.

59. Lambert M, Jambon S, Depauw S and David-Cordonnier MH: Targeting transcription factors for cancer treatment. Molecules 23: 1479, 2018

60. Peng $\mathrm{C}$, Zhang $\mathrm{W}$, Zhao $\mathrm{W}$, Zhu J, Huang $\mathrm{X}$ and Tian J: Alcohol-induced histone $\mathrm{H} 3 \mathrm{~K} 9$ hyperacetylation and cardiac hypertrophy are reversed by a histone acetylases inhibitor anacardic acid in developing murine hearts. Biochimie 113: 1-9, 2015.

61. Peng C, Zhu J, Sun HC, Huang XP, Zhao WA, Zheng M, Liu LJ and Tian J: Inhibition of histone H3K9 acetylation by anacardic acid can correct the over-expression of Gata4 in the hearts of fetal mice exposed to alcohol during pregnancy. PLoS One 9: e104135, 2014.

62. Cardoso AC, Pereira AHM, Ambrosio ALB, Consonni SR, Rocha de Oliveira R, Bajgelman MC, Dias SMG and Franchini KG: FAK forms a complex with MEF2 to couple biomechanical signaling to transcription in cardiomyocytes. Structure 24: 1301-1310, 2016.

This work is licensed under a Creative Commons Attribution-NonCommercial-NoDerivatives 4.0 International (CC BY-NC-ND 4.0) License. 